\title{
Mechanism of the Cytolytic Effect of Streptolysin 0: Influence of Scavengers of Active Forms of Oxygen and Complexones on Erythrocyte Hemolysis
}

\author{
V. N. Nikandrov and T. N. Lapushkina
}

UDC 615.363-018.51:546.21:541.515

\begin{abstract}
Translated from Byulleten' Eksperimental'noi Biologii iMeditsiny, Vol. 115, № 3, pp. 277-278, March, 1993
\end{abstract}
Original article submitted September 15, 1992

Key Words: streptolysin; hemolytic activity; active forms of oxygen

Among the exotoxins mediating the pathogenicity of $\beta$ hemolytic streptococci, streptolysin $O$ deserves special attention. It is a $60-61 \mathrm{kD}$ protein, which can be inactivated by oxidizers, including molecular oxygen [1,5]. Streptolysin O induces erythrohemolysis, causes damage to leukocytes, macrophages, fibroblasts, cells of Ehrlich's ascites tumor, and a number of other cells $[1,5]$. It does not possess proteolytic or lypolytic activity. The mechanisms of the streptolysin O-mediated cytolytic effect are widely disputed. The capacity of cholesterol and some other steroids for inhibiting the cardiotoxic and hemolytic effect of streptolysin $O[1,5]$ invited a hypothesis about its detergentlike effect on biomembranes. At the same time, there are indications [8] that streptolysin $\mathrm{O}$ can alter the metabolic processes related to the osmotic stability of erythrocytes. The reactions of free-radical oxidation are known to be important mechanisms in membrane destabilization and the realization of cytolysis [7]. In this connection we proposed that the cytolytic effect of streptolysin $O$ may be mediated via active forms of oxygen.

The goal of this work was to study the effect of scavengers of active forms of oxygen on the streptolysin $\mathrm{O}$-induced lysis of rabbit erythrocytes.

\section{MATERIALS AND METHODS}

Partially purified (400 times enriched in specific activity) specimens of streptolysin $\mathrm{O}$ were obtained

Byelorussian Research Institute of Epidemiology and Microbiology, Minsk. (Presented by V. I. Votyakov, Member of the Russian Academy of Medical Sciences) from the culture fluid of $\beta$-hemolytic streptococcus, strain H46A, grown on a nutrient medium of complex composition supplemented with casein hydrolysate [4]. The biomass was sedimented by centrifugation, the supernatant was fractionated by the addition of ammonium sulfate, and the protein sediment was treated with polyethylene glycol-4000 as described earlier [6] and subjected to chromatography on a column with DEAE-cellulose ( $\mathrm{Cl}^{-}$-form). Elution was performed with $0.25 \mathrm{M}$ veronal buffer, $\mathrm{pH}$ 7.0 , containing $1 \mathrm{M} \mathrm{NaCl}$. Active fractions were dialysed against distilled water and stored at $-20^{\circ} \mathrm{C}$. The specific activity of the streptolysin $\mathrm{O}$ specimens corresponded to $60,000-80,000$ hemolytic units per milligram protein. Electrophoresis in $12.5 \%$ polyacrylamide gel in the presence of Na-dodecylsulfate and 2-mercaptoethanol [14] revealed two protein bands possessing hemolytic activity. This is in agreement with the ability of streptolysin $O$ to form aggregates [5]. Hemolytic activity was determined by $50 \%$ lysis of rabbit erythrocytes suspended in $\mathrm{NaCl}$-containing $0.126 \mathrm{M}$ phosphate buffer, $\mathrm{pH} 6.5$ [12]. Streptolysin $\mathrm{O}$ was activated using $0.2 \mathrm{M} \mathrm{Na}$ thioglycolate. Protein content was measured after Lowry [11]. The reagents used in the experiments were L-histidine, Ltryptophan, riboflavin, reagents for polyacrylamide gel (Reanal, Hungary), D-mannitol, nitrotetrazolium blue (Chemapol, Czechoslovakia), and sodium azide (Serva, Germany). Streptokinase was purified from the Russian-manufacture commercial preparation "Tseliase" by chromatography on a column with Cibacron blue F36A-Sepharose $6 \mathrm{~B}$ sorbent as described in detail 
earlier [2]. Other domestic reagents of especially pure or chemically pure quality were additionally purified before use. All experiments were performed in four or more replications. The results were statistically evaluated using Student's $t$ test.

\section{RESULTS}

The investigations showed that all the scavengers and complexones studied appreciably inhibited the streptolysin $\mathrm{O}$-induced lysis of rabbit erythrocytes (Table 1 ).

For instance, scavengers of singlet oxygen (sodium azide, tryptophan, histidine), of the hydroxyl radical (ethanol, mannite), and of superoxide (nitrotetrazolium blue) inhibited streptolysin-induced hemolysis by $40-70 \%$. Earlier we showed that another protein of $\beta$-hemolytic streptococci, streptokinase, can interact with the superoxide radical, which participates in the realization of its activatory function [3]. It was found that the addition of streptokinase to the reaction mixture also inhibits the intensity of hemolysis, with an efficiency comparable to that of nitrotetrazolium blue.

These data enable us to conclude that the hemolytic action of streptolysin $O$ may be realized with the aid of singlet oxygen and the hydroxyl and superoxide radicals.

It has been established that the processes of formation and transformation of active forms of oxygen in most cases are mediated by the participation of ions of metals with variable valency. Introduction into the reaction mixture of the complexones $\mathrm{O}$-phenanthroline and, èspecially, $\mathrm{Na}$ diethyldithiocarbamate markedly inhibits streptolysin O-mediated hemolysis.

Finally, the hemolytic activity of streptolysin $O$ is sharply inhibited in the presence of potassium ferricyanide and riboflavin (Table 1), which are oxidoreductants and serve, most probably, as electron acceptors.

Thus, streptolysin O-induced hemolysis is realized with the participation of active forms of oxygen. The pattern of scavenger action allows us to assume a role of several types of active forms of oxygen or else complex reactions of their mutual interconversions in hemolysis. Erythrocyte lysis is known to be able to occur via the combined action of $\mathrm{H}_{2} \mathrm{O}_{2}$ and $\mathrm{O}_{2}^{-}$, the interaction of which results in the formation of $\mathrm{OH}$ and singlet oxygen [10]. On the other hand, $\mathrm{H}_{2} \mathrm{O}_{2}$ and $\mathrm{O}_{2}^{-}$rather freely pass across the cell membrane, and the situation is changed only in the presence of a number of metalloproteins promoting $\mathrm{OH}$. generation [13]. In general, this is in agreement with the inhibitory effect of phenanthroline and $\mathrm{Na}$ diethylthiocarbamate on the hemolytic activity of streptolysin $\mathrm{O}$.
TABLE 1. Changes in Hemolytic Activity of Streptolysin $O$ Caused by Active Oxygen Scavengers, Complexones and Oxidoreductants

\begin{tabular}{l|c}
\hline \multicolumn{1}{c|}{ Agent } & $\begin{array}{c}\text { Hemolytic activity, } \\
\% \text { of control level }\end{array}$ \\
\hline Control (no agents) & 100 \\
Sodium azide, $10^{-3} \mathrm{M}$ & $67.7 \pm 10.6$ \\
L- histidine, $10^{-2} \mathrm{M}$ & $32.4 \pm 4.8$ \\
L-tryptophan, $10^{-2} \mathrm{M}$ & $39.4 \pm 9.4$ \\
Ethanol, 1.7 $\mathrm{M}$ & $38.4 \pm 9.4$ \\
$3.4 \mathrm{M}$ & $28.4 \pm 9.1$ \\
D-mannitol, $10^{-2} \mathrm{M}$ & $47.4 \pm 13.8$ \\
Nitrotetrazolium blue, 10-4 M & $43.2 \pm 5.9$ \\
Streptokinase, $5000 \mathrm{IU}$ & $47.7 \pm 9.2$ \\
O-Phenanthroline, $6 \times 10^{-4} \mathrm{M}$ & $32.4 \pm 2.9$ \\
Sodium diethyldithiocar- & $17.5 \pm 4.8$ \\
$\quad$ bamate, $10^{-3} \mathrm{M}$ & $21.3 \pm 4.0$ \\
K Fe[CN], $5 \times 10^{-5} \mathrm{M}$ & $30.6 \pm 8.8$ \\
Riboflavin, $4 \times 10^{-6} \mathrm{M}$ & \\
\hline
\end{tabular}

The revealed effects of active oxygen scavengers may reflect their action both on the toxin molecule and on the metabolic processes in the erythrocyte. There is no information in the literature regarding the presence of metal ions in the streptolysin $\mathrm{O}$ molecule, nor on its participation in oxidative-reduction reactions. The functional role of the toxin for the streptococcal cell is unclear. However, the processes of generation of active forms of oxygen in the erythrocytes are well known. The notion about their participation in the hemolytic action of streptolysin $\mathrm{O}$ does not contradict the known data on the inhibition of such hemolysis by cholesterol. Toxin-cholesterol interaction is considered to be the initial stage of hemolysis $[8,9]$, whereas the subsequent mechanism remains obscure.

The data obtained open up prospects for the study of the role of streptolysin $O$ in the electrontransport processes and the processes dependent on active forms of oxygen, and allow us to envisage new approaches to working out ways of controlling streptolysin $\mathrm{O}$-induced toxic damage to tissues and organs.

\section{REFERENCES}

1. M. V. Dalin and N. G. Fish, Microbial Toxins of Protein Nature [in Russian], Moscow (1980).

2. V. N. Nikandrov, N. S. Pyzhova, V. I. Votyakov, et al., Dokl. Akad. Nauk BSSR, 30, № 11, 1033-1036 (1986).

3. V. N. Nikandrov, G. V. Vorob'eva, G. S. Yankovskaya, et al., Izv. Akad. Nauk BSSR, Ser. Biol. Nauk, № 5, 73-79 (1990).

4. N. L. Shatilo, Patterns of Streptokinase Accumulation in Multistage In-Depth Culturing of Group C Streptococcus on Nutrient Media Supplemented with Caseine Hydro1ysate: Abstract of Doctor of Biological Science dissertation, Moscow (1990).

5. J. E. Alouf, Pharmacol. Ther., 11, 661 (1980). 
6. S. Bhakdi, M. Roth, A. Sziegoleit, and J. TranumJensen, Infect. Immun., 46, 394-400 (1984).

7. R. T. Dean, Brit. J. Cancer, 55, Suppl. 8, 39-45 (1987).

8. M. K. Johnson and K. S. Aultman, J. Gen. Microbiol., 101, № 2, 237-241 (1977).

9. Y. Kanbayashi, M. Hotta, and J. Kogama, J. Biochem. (Tokyo), 71, № 2, 227-237 (1972).

10. E. W. Kellogg and J. Fridovich, J. Biol. Chem., 252,
№ 19, 6721-6728 (1977).

11. O. H. Lowry, N. J. Rosebrough, A. L. Farr, and R. J. Randall, Ibid., 193, № 1, 265-275 (1951).

12. T. D. Oberly and Y. L. Duncan, Infect. Immun., № 4, 683-687 (1971).

13. G. M. Vercelotti, B. S. Van Asbeck, and H. S. Jacob, J. Clin. Invest., 76, 956-962 (1985).

14. K. Weber and M. Osborn, J. Biol. Chem., 244, № 16, 4406-4412 (1969).

\title{
Analysis of the Immunomodulating Effect of SK in Mice of Different Strains
}

\author{
E. I. Zlishcheva, G. B. Krillicheva, A. Ya. Shurygin, \\ I. G. Baturina, and G. L. Ratgauz
}

UDC 615.276.2.076.9

Translated from Byulleten' Eksperimental'noi Biologii i Meditsiny, Vol. 115, № 3, pp. 278-280, March, 1993 Original article submitted October 13, 1992

Key Words: SK immunomodulator; 5'-nucleotidase; macrophages; resistance to staphylococcal infection; interstrain differences

In recent years immunomodulators enhancing nonspecific rèsistance have been increasingly more widely used for a directed influence on immune reactions and for the correction and regulation of immune processes [3]. This poses the problem of the optimal choice of agents in the context of a given infection, and the elaboration of optimal dosages and regimens. At Kuban State University a new immunomodulator of microbial origin has been obtained. The preparation, named SK, represents a mixture of polypeptides with a molecular weight in the range of 500 to $4000 \mathrm{D}$ [6].

Our aim was to study specific features of the immunomodulatory effect of SK in mice of different strains. Immunomodulatory activity was assessed according to the changes in: a) the 5 '-nucleotidase (5'$\mathrm{N})$ activity in the peritoneal exudate macrophages

Kuban State University, Krasnodar; N.F. Gamaleya Research Institute of Epidemiology and Microbiology, Russian Academy of Medical Sciences, Moscow. (Presented by A. D. Ado, Member of the Russian Academy of Medical Sciences)
(PEM) and b) the susceptibility of mice to infection with Staphylococcus aureus strain Wood-46. There is some information indicating significance of $5^{\prime}-\mathrm{N}$ for nucleotide assimilation, energy supply of the cells, and the implementation of genetic information $[5,9,10]$. The product of the enzymatic reaction, adenosine, is considered today to be one of the main regulators of vital physiological functions, including the work of the immune system $[7,11]$.

\section{MATERIALS AND METHODS}

Male mice of the CBA and $\mathrm{C} 57 \mathrm{Bl} / 6$ strains weighing 16-18 $\mathrm{g}$ were used. The animals received a single subcutaneous (sc) or intraperitoneal (ip) injection of SK, $0.2 \mu \mathrm{g}$ or $5 \mu \mathrm{g}$ per mouse. The following day ecto- $5^{\prime}-\mathrm{N}$ activity in the PEM was determined according to a modified method [4]. At this time the mice were given sc $2.5 \times 10^{9}, 5 \times 10^{9}$ or $10 \times 10^{9}$ cells from a one-day culture of St. aureus strain Wood46. The mice were observed for 15 days. The effect 